\title{
Effects of KF-14363 on Liver Fibrosis in Rats with Chronic Liver Injury Induced by Carbon Tetrachloride
}

\author{
Ikufumi YOSHITAKE, Eiko OHISHI, Junichi SANO, Tatsuya MORI, and Kazuhiro KUBO
}

Pharmaceutical Research Laboratories Kyowa Hakko Kogyo Co., Ltd., Shimotogari, Nagaizumicho, Sunto-gun, Shizuoka 411, Japan

(Received July 15, 1991)

\begin{abstract}
The present study examined the effects of (1-[(2-thiazolin-2-yl)amino]-acetyl-4-(1,3-dithiol2-ylidene)-2,3,4,5-tetrahydro-1 $H$-1-benzazepin-3,5-dione hydrochloride (KF-14363) on liver fibrosis in rats with chronic liver injury induced by carbon tetrachloride $\left(\mathrm{CCl}_{4}\right)$.

Liver injury in male rats was induced by repeated administration of $\mathrm{CCl}_{4}$ at $0.5 \mathrm{ml} / \mathrm{kg}$ twice a week. The progression of liver fibrosis was checked in the 4 th, 6 th, 8 th and 10 th weeks using the relative amount of hepatic 4-hydroxy proline (4-hyp) to total proteine as an index of hepatic collagen. The relative amount of hepatic 4-hyp in these rats exceeded significantly that in rats not administered $\mathrm{CCl}_{4}$ by the 4 th week. This progressed in proportion to the duration of $\mathrm{CCl}_{4}$ administration. In groups concurrently administered KF-14363 at 30 and $100 \mathrm{mg} / \mathrm{kg} / \mathrm{d}$ from the 5 th or 8th week of the $\mathrm{CCl}_{4}$ administration, the relative amount of hepatic 4-hyp was found to be lower in the 10th week than at the start of the KF-14363 administration. The inhibition of liver fibrosis was also observed histopathologically. The concurrently co-administration with $\mathrm{CCl}_{4}$ or $\mathrm{KF}-14363$ at 30 and $100 \mathrm{mg} / \mathrm{kg}$ for 2 or 5 weeks inhibited the increases in serum transaminases and alkaline phosphatase induced by $\mathrm{CCl}_{4}$.

The results show that KF-14363 inhibits liver fibrosis in a dose dependent fashion in rats with progressive liver injury.
\end{abstract}

Keywords - hepatoprotection; rat liver fibrosis; 4-hydroxyproline; carbon tetrachloride

\section{Introduction}

It is known that KF-14363 (1-[(2-thiazolin2-yl)amino]-acetyl-4-(1,3-dithiol-2-ylidene)-2, 3,4,5-tetrahydro- $1 H$-1-benzazepin-3,5-dione hydrochloride, Fig.1) is effective in inhibiting in acute liver injury in various experimental models ${ }^{1}$ : (such as carbon tetrachloride $\left(\mathrm{CCl}_{4}\right)$, D-galactosamine (D-gal), DL-ethionine, D-gal plus lipopolysaccharide (LPS) and heat-treated Propionibacterium acnes plus LPS models.).

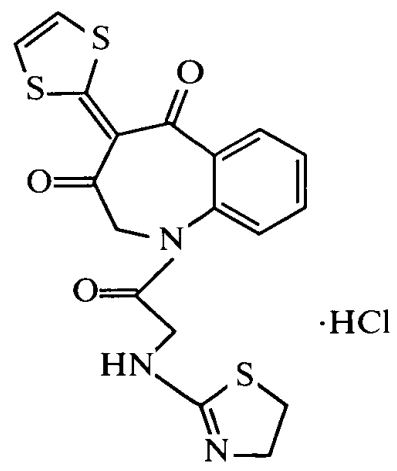

Fig. 1. Chemical Structure of KF-14363
Furthermore it reports that the inhibition of radical production plays an important role in this hepatoprotective effects. ${ }^{2)}$

It is also known that KF-14363 accelerates liver regeneration through a mechanism of activating the liver energy generating system, especially for the production of high energy phosphate compounds, by enhancement of the mitochondrial respiratory activity (unpublished data).

The present study was conducted to investigate the therapeutic effect of $\mathrm{KF}-14363$ in the chronic liver injury model induced by $\mathrm{CCl}_{4}$.

\section{Materials amd Methods}

1. Animals - Animals used in this study were Sprague-Dawley (SD) male rats (Nippon Clea) of 6 weeks of age. Rats were kept 2 rats/cage and allowed free access to pellet food (F-2, Funabashi Farm) and water.

2. Drug - KF-14363 (lot BH-3066) was synthesized by Kyowa Hakko Kogyo Co., Ltd. KF-14363 was suspended in $4 \%$ aqueous gum 


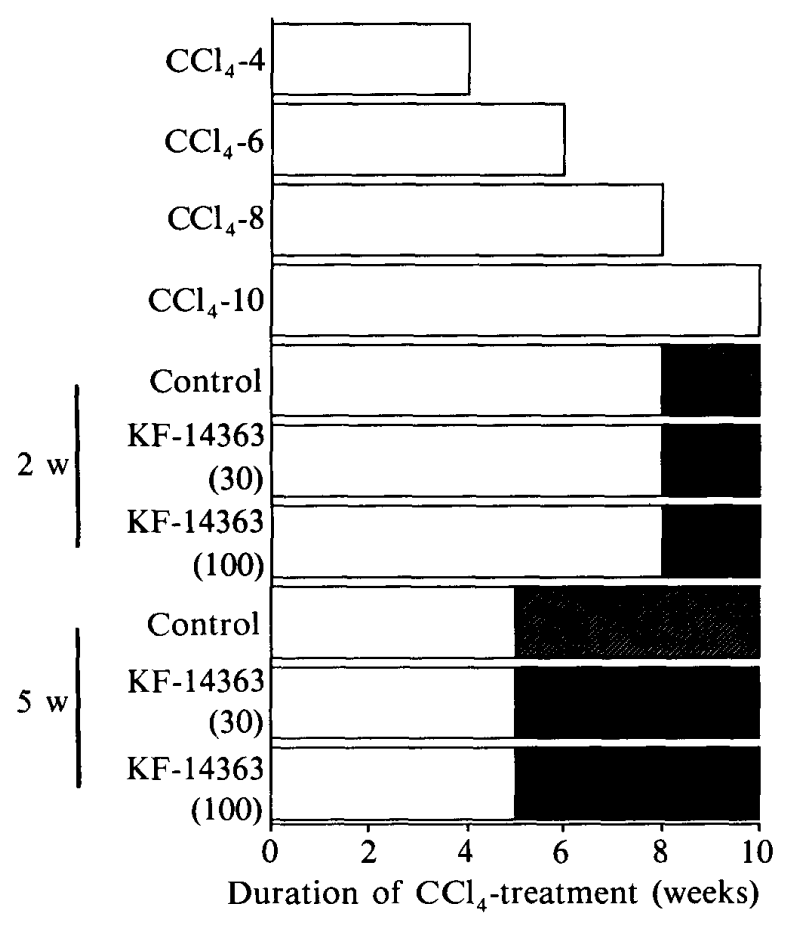

Fig. 2. Experimental Schedule for Studying the Effect of $\mathrm{KF}-14363$ on $\mathrm{CCl}_{4}$-Induced Chronic Liver Injury

For details, see the Materials and Methods section.

$\square, \mathrm{CCl}_{4} ; \mathscr{W}, \mathrm{CCl}_{4}+$ vehicle; $\mathrm{I}, \mathrm{CCl}_{4}+\mathrm{KF}-14363$

$(30 \mathrm{mg} / \mathrm{kg}) ; \mathbf{\square}, \mathrm{Cl}_{4}+\mathrm{KF}-14363(100 \mathrm{mg} / \mathrm{kg})$.

arabic solution.

\section{Induction of Chronic Liver Injury Induced} by $\mathrm{CCl}_{4}{ }^{3)}$ and Administration of $\mathrm{KF}-14363$ $\mathrm{CCl}_{4}$ (Kanto Chemical Co., Inc.) was mixed with olive oil to make $10 \%(\mathrm{w} / \mathrm{v})$, and $5 \mathrm{ml} / \mathrm{kg}$ of the mixture $\left(0.5 \mathrm{ml} / \mathrm{kg}\right.$ as $\left.\mathrm{CCl}_{4}\right)$ was injected intraperitoneally into rats twice a week (Tuesday and Friday) for 10 weeks to induce chronic liver injury. After the end of the 4th and 7 th week of injection of the $\mathrm{CCl}_{4}$ solution, these rats were divided into 3 groups and given orally once a day either 30 or $100 \mathrm{mg} / \mathrm{kg} / \mathrm{d}$ or $4 \%$ aqueous gum arabic solution until $3 \mathrm{~d}$ after the last administration of the 10 th week of $\mathrm{CCl}_{4}$. Rats in other groups were treated with $\mathrm{CCl}_{4}$ alone and were sacrificed in the 4th, 6th, 8th and 10th week. Figure 2 shows the administration schedule.

The following day after the last administration of $\mathrm{CCl}_{4}$, blood samples were taken from the abdominal aorta of rats under anesthesia with ether, and the liver was then isolated. The large median lobe of the liver was resected, fixed in $10 \%$ neutral formalin solution and used for histological study. The left lateral lobe was resected, homogenized with $1.15 \%$ potassium

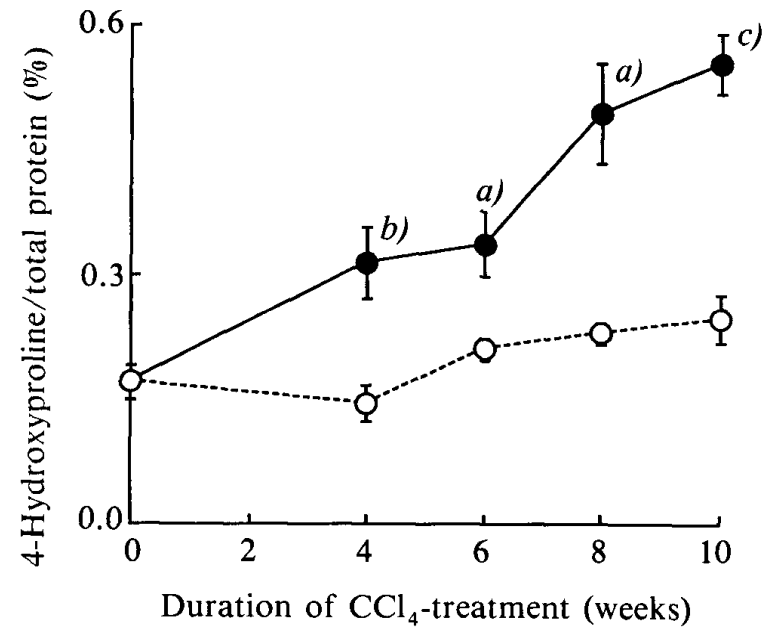

Fig. 3. Periodic Changes in the Ratio of Hepatic 4-Hydroxyproline to Total Hepatic Protein in Rats with Chronic Liver Injury Induced by $\mathrm{CCl}_{4}$

Each point represents the mean \pm S.E. of 5 (4-8 weeks) or 12 (10 weeks) rats. a) $p<0.05$, b) $p<0.01$ and c) $p<0.001$., $\mathrm{CCl}_{4} ; \bigcirc$, normal.

chloride solution and used for determination of 4-hydroxyproline (4-hyp). Blood samples were centrifuged $(1900 \times \mathrm{g}, 10 \mathrm{~min})$, and the serum was analyzed using a biochemical automatic analyzer (Model AU510, Olympus) for glutamate pyruvate transaminase (GPT), glutamate oxaloacetate transaminase (GOT) and alkaline phosphatase (ALP). The protein content of the liver homogenate was determined using a protein assay kit (Bio-Rad). Liver homogenate was hydrolyzed $\left(6 \mathrm{~N} \mathrm{HCl}, 110{ }^{\circ} \mathrm{C}, 20 \mathrm{~h}\right)$ and hydroxy proline quantitatively determined by the method of Neuman and Logan. ${ }^{4)}$

For histopathological examination, the formalin fixed liver was embedded in paraffin, sectioned, subjected to hematoxylin-eosin stain and Masson's trichrome stain, and observed under an optical microscope. The incidence and degree of cell proliferation, vacuolation and ballooning were scored as normal $(-)$, very slight $(+)$, slight $(++)$, moderate $(+++)$ or severe $(++++)$.

4. Statistical Analysis - Values were expressed as the mean \pm S.E. For comparison between 2 groups, the Student's $t$-test, AspinWelch test or Cochran test was used, and for the tests between multiple groups, the Dunnet test or Scheffe test was used. The $p<0.05$ was judged to be significant. 
TABLE I. Periodic Changes in Histological Findings in Rats with Chronic Liver Injury Induced by $\mathrm{CCl}_{4}$

\begin{tabular}{|c|c|c|c|c|c|c|c|c|c|c|}
\hline \multirow[b]{2}{*}{ (weeks) } & \multicolumn{5}{|c|}{ Fibrosis } & \multicolumn{5}{|c|}{ Vacuolation, ballooning } \\
\hline & - & + & ++ & +++ & ++++ & - & + & ++ & $+t+$ & +++ \\
\hline 4 & 1 & 3 & 1 & & & 1 & 3 & 1 & & \\
\hline 6 & & 2 & 2 & 1 & & & & 2 & 3 & \\
\hline 8 & & & 3 & 2 & & & & 1 & 3 & 1 \\
\hline 10 & & & 4 & 3 & 5 & & 3 & 6 & 3 & \\
\hline
\end{tabular}

Grade designation of the histological findings; $(-)$ normal, $(+)$ very slight, $(++)$ slight, $(+++)$ moderate, $(++++)$ severe. Each value is the number of animals with grading changes. For details, see the Materials and Methods section in the text and Fig.2.

TABlE II. Effects of KF-14363 on Three Serum Parameters and the Ratio of Hepatic 4-Hydroxyproline to Total Hepatic Protein in Rats with Chronic Liver Injury Induced by $\mathrm{CCl}_{4}$

\begin{tabular}{lccccc}
\hline & $\begin{array}{c}\text { Duration of } \\
\text { administration (week) }\end{array}$ & $\begin{array}{c}\text { GPT } \\
(\mathrm{IU} / \mathrm{l})\end{array}$ & $\begin{array}{c}\text { GOT } \\
(\mathrm{IU} / \mathrm{l})\end{array}$ & $\begin{array}{c}\text { ALP } \\
(\mathrm{IU} / \mathrm{l})\end{array}$ & $\begin{array}{c}\text { 4-hyp/TP } \\
(\%)\end{array}$ \\
\hline Control & - & $55.2 \pm 7.9$ & $139.3 \pm 7.8$ & $528.5 \pm 47.8$ & $0.49 \pm 0.04$ \\
$\mathrm{KF}-14363(30 \mathrm{mg} / \mathrm{kg})$ & 2 & $29.8 \pm 5.0^{b j}$ & $\left.105.2 \pm 4.9^{a}\right)$ & $406.1 \pm 73.4$ & $0.35 \pm 0.03^{a j}$ \\
$\mathrm{KF}-14363(100 \mathrm{mg} / \mathrm{kg})$ & 2 & $28.9 \pm 1.9^{b j}$ & $94.3 \pm 6.7^{b j}$ & $300.2 \pm 8.0^{a)}$ & $0.32 \pm 0.02^{b)}$ \\
& & & & & \\
Control & - & $60.0 \pm 8.9$ & $121.4 \pm 20.5$ & $452.6 \pm 36.6$ & $0.51 \pm 0.06$ \\
$\mathrm{KF}-14363(30 \mathrm{mg} / \mathrm{kg})$ & 5 & $24.8 \pm 1.0^{b)}$ & $115.7 \pm 7.9$ & $286.0 \pm 24.2^{b)}$ & $0.30 \pm 0.02^{b)}$ \\
$\mathrm{KF}-14363(100 \mathrm{mg} / \mathrm{kg})$ & 5 & $24.7 \pm 2.5^{b)}$ & $106.5 \pm 8.4$ & $270.5 \pm 19.1^{b)}$ & $0.26 \pm 0.02^{b)}$ \\
\hline
\end{tabular}

Each value represents the mean \pm S.E. of 6 or 7 rats. Significantly different from the control value, $a$ ) $p<0.05$ and b) $p<0.01$. For details, see the Materials and Methods section in the text and Fig. 2 .

\section{Results}

\section{Progression of Liver Fibrosis by Repeated Ad- ministration of $\mathbf{C C l}_{4}$}

Changes in the relative amount of hepatic 4-hydroxyproline (4-hyp) to total protein (TP) and the pathological examination in the liver were measured $4,6,8$, and 10 weeks after initiation of $\mathrm{CCl}_{4}$ administration. The relative amount of 4-hyp increased significantly in proportion to the duration of $\mathrm{CCl}_{4}$ administration, and the increase from the normal value was significant in $\mathrm{CCl}_{4}$ treated groups (Fig. 3). The relative amount of hepatic 4-hyp in the 8th week of $\mathrm{CCl}_{4}$ administration became more than twice compared with normal group. Pathological examination showed vacuolation and ballooning of the liver with slight proliferation of fibrosis from the 4th week of $\mathrm{CCl}_{4}$ (Table I). In the 6th to 8th week, vacuolation and ballooning of the liver peaked, and while liver fibrosis advanced to par- tial formation of pseudolobules. In the 10th week, though vacuolation and ballooning of the liver were slightly improved, the formation of pseudolobules became more remarkable, and hepatic cirrhosis was seen in some rats.

\section{Effect of KF-14363 on Liver Fibrosis}

The effect of KF-14363 on the relative amount of hepatic 4-hyp to total protein was studied in rats treated with this drug from the 5th or 8th week to the 10th week (for 5 or 2 weeks) of $\mathrm{CCl}_{4}$ administration (Table II). In the 2-weektreated groups, the decrease in 4-hyp was significant as compared with the values of the control group treated with the vehicle. In the groups receiving KF-14363 for 5 weeks, the relative amount of 4-hyp was more remarkably lower.

The effect of KF-14363 on serum liver parameters was studied (Table II). In the 2-weektreated groups, GPT was lower than that in the control group given the vehicle. Also in the groups given KF-14363 for 5 weeks, the lower- 


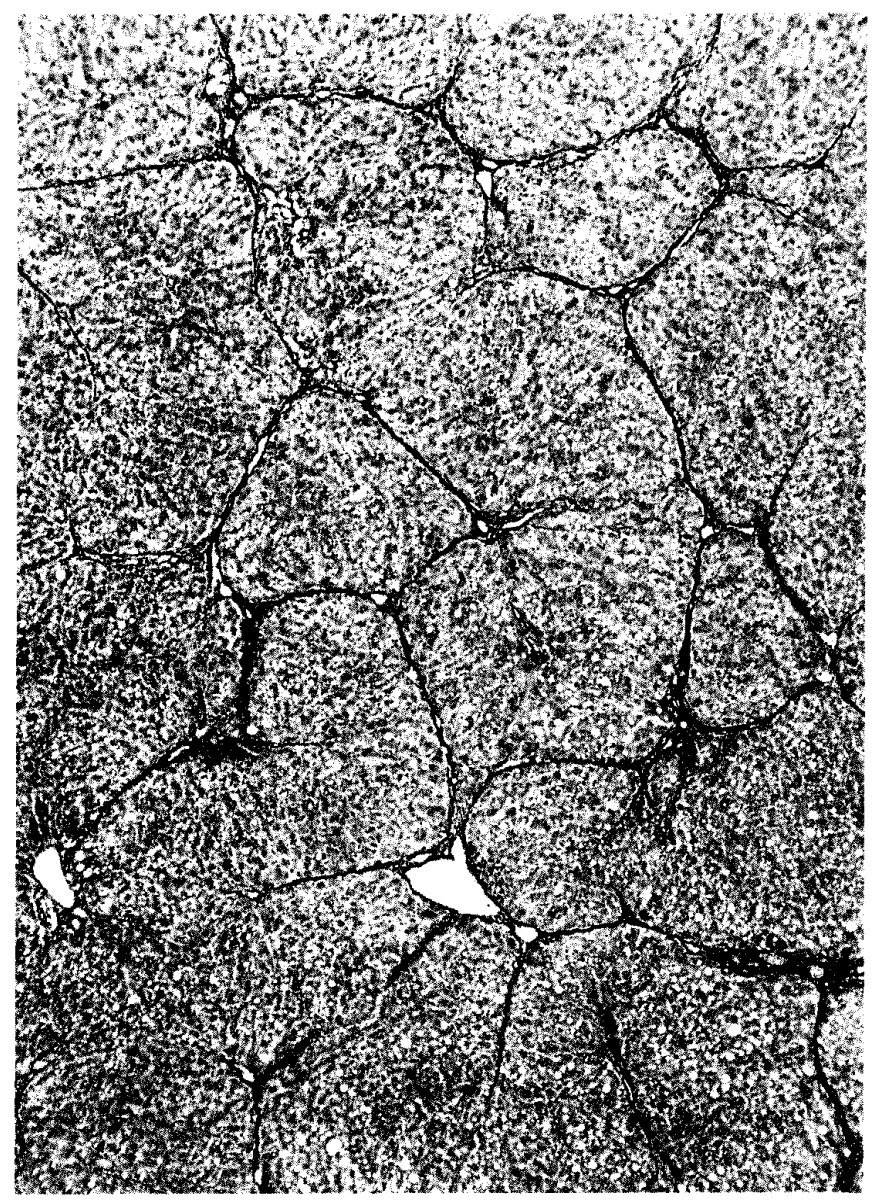

Fig. 4. Photograph of the Rat Liver Treated with $\mathrm{CCl}_{4}$ Twice a Week for 10 Weeks

Formation of fibrous septa is apparent. (Masson's trichrome stain; $\times 40$ ).

ing of GPT was significant $(p<0.01)$ as compared with the control group. KF-14363 (30 and $100 \mathrm{mg} / \mathrm{kg} / \mathrm{d}$ ) reduced significantly the GOT increase in the 2-week-treated groups, but any significant difference was not observed in the 5-week-treated groups because of a wide variation of GOT values in the control group. ALP was lower in the 2-week-treated group of 100 $\mathrm{mg} / \mathrm{kg} / \mathrm{d}$ with a significant difference $(p<0.05)$, but not in the 2-week-treated group of 30 $\mathrm{mg} / \mathrm{kg} / \mathrm{d}$. In the 5-week-treated groups, the increase in ALP was significantly lower than that in the control group.

Pathological evaluation of the liver revealed that $\mathrm{KF}-14363$ at 30 and $100 \mathrm{mg} / \mathrm{kg} / \mathrm{d}$ for 2 weeks inhibited liver fibrosis dose-dependently (Fig. 4-6, Table III). In KF-14363 groups for 5 weeks, the inhibition of liver fibrosis was so

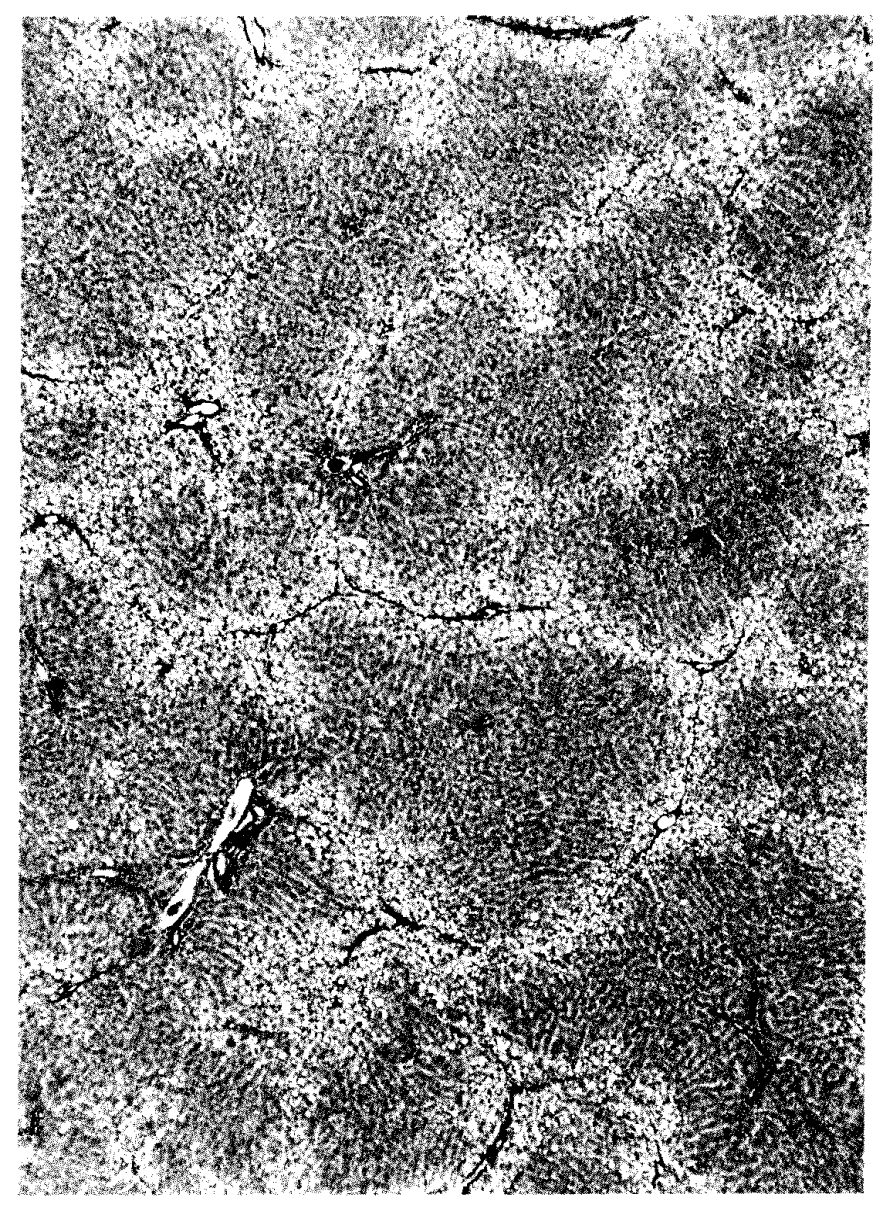

Fig. 5. Photograph of the Rat Liver Given KF-14363 (30 $\mathrm{mg} / \mathrm{kg} / \mathrm{d}$, p.o.) in the Period from 5 to 10 Weeks of $\mathrm{CCl}_{4}$ Administration (Twice a Week for 10 Weeks)

Fibrosis is recognized around the hepatic vessels. (Masson's trichrome stain; $\times 40$ ).

remarkable that only a very slight proliferation of fibrosis was observed, and the liver was normal in some cases.

\section{Discussion}

Acute high-dose administration of $\mathrm{CCl}_{4}$ induces centrilobular necrosis, but chronic lowdose administration induces liver injury and accelerates fibrosis by degenerating hepatic cells and inhibiting their regeneration, resulting in hepatic cirrhosis. ${ }^{5-10)}$ In such liver injury, the trichloro methyl carbon radical $\left(\cdot \mathrm{CCl}_{3}\right)$ produced by drug metabolizing enzymes in liver microsomes plays an important role. ${ }^{7,9)}$ In this study, investigation of the progress of liver injury due to repeated administration of $\mathrm{CCl}_{4}$ showed a significant increase in the relative 


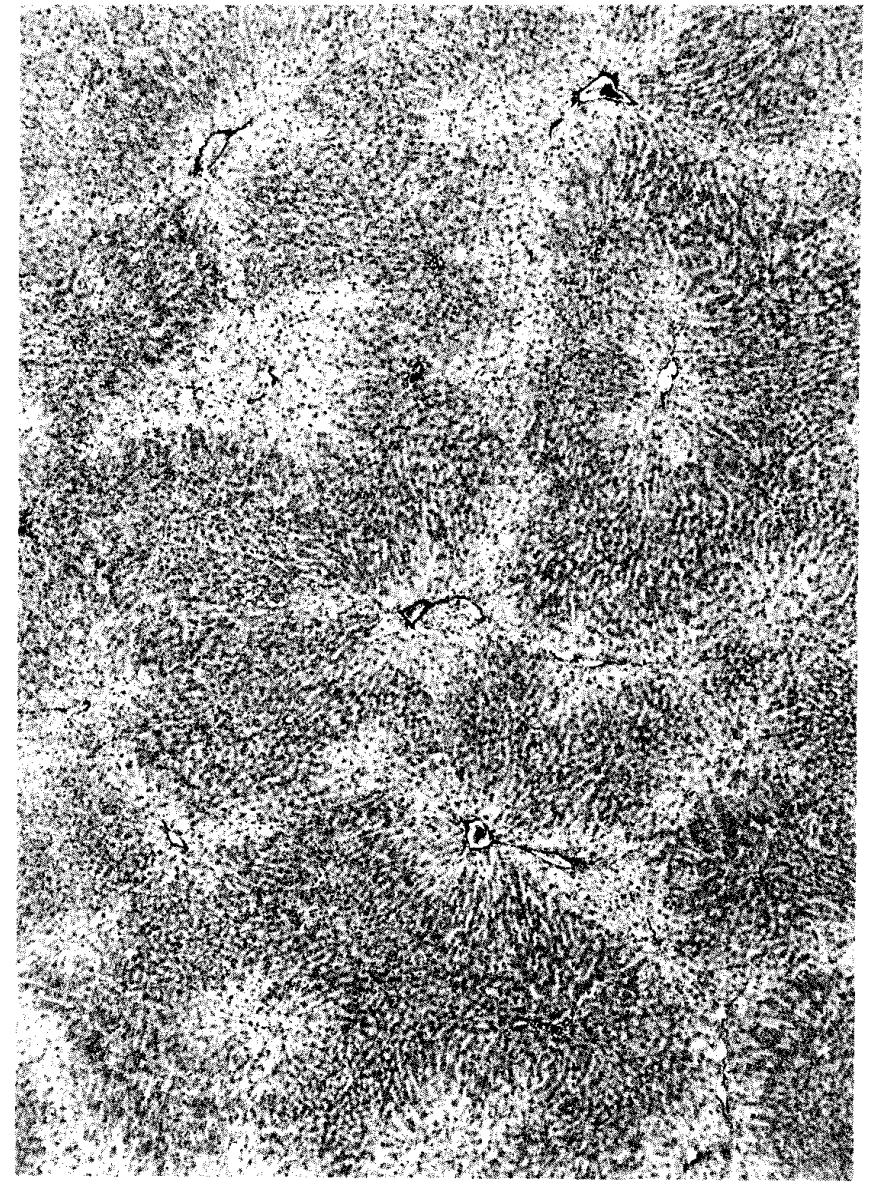

Fig. 6. Photograph of the Rat Liver Given KF-14363 (100 $\mathrm{mg} / \mathrm{kg} / \mathrm{d}$, p.o.) for the Last 5 Weeks in Paralled with $\mathrm{CCl}_{4}$ Twice a Week for 10 Weeks

Prominent reduction of fibrous component is recognized. (Masson's trichrome stain; $\times 40$ ).

amount of 4-hyp to total protein, indicating liver fibrosis, ${ }^{11)}$ compared with the amount in the normal group in the 4 th week of $\mathrm{CCl}_{4}$ adminis- tration, as well as a slight proliferation of fibrosis histopathologically. In the present examination on the progress of liver injury by repeated administration of $\mathrm{CCl}_{4}$, vacuolation and ballooning in the liver cells peaked in the 6th to 8th week of $\mathrm{CCl}_{4}$ administration and slightly improved by the 10 th week. This bell-shaped tendency coincides with that described in Katoh and Sugimoto's report. ${ }^{3)}$ The consecutive administration of KF-14363 at 30 and $100 \mathrm{mg} / \mathrm{kg} / \mathrm{d}$ from the 5th or 8th week of $\mathrm{CCl}_{4}$ administration inhibited liver fibrosis. This finding suggests that KF-14363 may inhibit or improve the progression of fibrosis in the chronically injured liver. It is known that KF-14363 has an inhibitory effect on the production of active oxygens by various stimulants (arachidonic acid, $\mathrm{CCl}_{4}$ and $\mathrm{Ca}^{2+}$ ionophore) in peritoneal exudate cells in the rat. ${ }^{2)}$ It is considered that such an inhibitory effect on production of these radicals may play an important role in the mechanism of action of KF-14363 observed in the present experiment on chronic liver injury.

Improvement by KF-14363 was shown also in serum biochemical parameters. However, the changes in serum biochemical parameters in chronic liver injury are less than those in the acute case. The reason seems that, by the 10th week of $\mathrm{CCl}_{4}$ administration, the liver is already in such a condition that enzyme extrication is reduced due to the proliferation of liver fibrosis resulting from the extrication of intracellular enzymes at early stages of $\mathrm{CCl}_{4}$ administration. This phenomenon is seen also in clinical

TABLE III. Effect of KF-14363 on Histological Changes in the Liver of Rats with Chronic Liver Injury Induced by CCl 4

\begin{tabular}{|c|c|c|c|c|c|c|c|c|c|c|c|}
\hline & \multirow{2}{*}{$\begin{array}{c}\text { Duration of } \\
\text { administration (week) }\end{array}$} & \multicolumn{5}{|c|}{ Fibrosis } & \multicolumn{5}{|c|}{ Vacuolation, ballooning } \\
\hline & & - & + & ++ & +++ & ++++ & - & + & ++ & +++ & +++ \\
\hline Control & - & & & 1 & 3 & 3 & & 1 & 4 & 2 & \\
\hline $\mathrm{KF}-14363(30 \mathrm{mg} / \mathrm{kg})$ & 2 & & 3 & 2 & 2 & & & 1 & 2 & 4 & \\
\hline $\mathrm{KF}-14363(100 \mathrm{mg} / \mathrm{kg})$ & 2 & & 4 & 1 & 2 & & & 5 & 1 & 1 & \\
\hline Control & - & & & 2 & 4 & 1 & & 4 & 2 & 1 & \\
\hline $\mathrm{KF}-14363(30 \mathrm{mg} / \mathrm{kg})$ & 5 & & 6 & & & & & & 3 & 3 & \\
\hline $\mathrm{KF}-14363(100 \mathrm{mg} / \mathrm{kg})$ & 5 & 2 & 5 & & & & & 1 & 4 & 2 & \\
\hline
\end{tabular}

Grade designation of the histological findings; $(-)$ normal, $(+)$ very slight, $(++)$ slight, $(+++)$ moderate, $(++++)$ severe. Each value is the number of animals with grading changes. For details, see the Materials and Methods section in the text and Fig. 2. 
cases of chronic liver injury where enzyme extrication into blood is lower than in acute one. ${ }^{12)} \mathrm{KF}-14363$ didn't reduce significantly the GOT increase. This might also be because the GOT value was considerably varied. And also GOT is not a liver specific emzyme compared with GPT. ${ }^{13)}$

In connection with the inhibitory effect of KF-14363 on the manifestation of chronic liver injury due to administration of $\mathrm{CCl}_{4}$, Mourelle et al. ${ }^{14)}$ reported that $\mathrm{BW} 755 \mathrm{C}$, cyclooxygenase and lipoxygenase inhibitors, and indomethacin, a cyclooxygenase inhibitor, had an inhibitory effect on liver cirrhosis caused by $\mathrm{CCl}_{4}$ administration. The effect was stronger with $\mathrm{BW} 755 \mathrm{C}$ and lower with indomethacin than with colchicine ${ }^{15,16)}$ which is known for its inhibitory effect on liver fibrosis. Colchicine has been reported to inhibit the synthesis of leukotriene ${ }^{17)}$ but to enhance the production of prostaglandin. ${ }^{18)}$ According to the report by Mourelle et al., ${ }^{14)}$ BW755C inhibited fibrosis more strongly than did indomethacin, and therefore, they reported the importance to the lipoxygenase route in liver cirrhosis. It is known that KF-14363 inhibits radical production by arachidonic acid in intraperitoneal exudative cells ${ }^{2}$ ) and that the lipoxygenase route takes part in the radical production by arachidonic acid. ${ }^{19,20)}$ Accordingly, the inhibition of radical production in the lipoxygenase route may be regarded as a factor in the inhibitory effect of KF-14363 on chronic liver injury.

As described above, KF-14363 at 30 or 100 $\mathrm{mg} / \mathrm{kg} / \mathrm{d}$ inhibited liver fibrosis dose- and duration-dependently in rats with liver injury induced by $\mathrm{CCl}_{4}$ and has therapeutic effects on chronic liver injury, including the inhibition of, aggravation of and the improvement of $\mathrm{CCl}_{4}$-induced chronic liver injury.

\section{Acknowledgements}

The authors are grateful to Ms. Mayumi Ito for her excellent technical assistance.

\section{References}

1) I. Yoshitake, E. Ohishi and K. Kubo: Hepatoprotective effects of 1-[(2-thiazolin-2-yl)amino]acetyl-4-(1,3- dithiol-2-ylidene)-2,3,4,5-tetra-hydro-1 $H$-1-benzazepin3,5-dione hydrochloride (KF-14363) in various experimental liver injuries, Jpn. J. Pharmacol., 57, 127-136 (1991).

2) I. Yoshitake and K. Kubo: Hepatoprotective effects of 1-[(2-thiazolin-2-yl)amino]acetyl-4-(1,3-dithiol-2-ylidene)-2,3,4,5-tetrahydro-1 $H$-1-benzazepin-3,5-dione hydrochloride (KF-14363) on activated oxygen production, Jpn. J. Pharmacol., 57, 137-145 (1991).

3) M. Katoh and T. Sugimoto: Effect of malotilate on chronic liver injury induced by carbon tetrachloride in rats, Folia Pharmacol. Jpn., 80, 83-91 (1982).

4) R. E. Neuman and M. A. Logan: The determination of hydroxyproline, J. Biol. Chem., 184, 299-306 (1950).

5) K. Aterman: Studies in fibrosis of the liver induced by carbon tetrachloride, Arch. Pathol., 57, 1-11 (1954).

6) G. R. Cameron and W. A. E. Karunaratne: Carbon tetrachloride cirrhosis in relation to liver regeneration, $J$. Pathol. Bact., 42, 1-21 (1936).

7) R. O. Recknagel: Carbon tetrachloride hepatotoxicity, Pharmacol. Rev., 19, 145-208 (1967).

8) E. Nagata: Electron microscopic and biochemical study of experimental hepatic necrosis induced by $\mathrm{CCl}_{4}$, Acta Hepatol. Jpn., 20, 261-272 (1979).

9) T. F. Slater and B. C. Sawyer: The stimulatory effects of carbon tetrachloride and other halogeno-alkanes on peroxidative reactions in rat liver fractions in vitro, Biochem. J., 123, 805-814 (1971).

10) K. Umezu, S. Sudoh and M. Inagaki: Suppressive effect of tritoqualine (TRQ) on the acceleration of fibrosis in the liver, Folia Pharmacol. Jpn., 87, 291-300 (1986).

11) K. Fujisawa: Liver injury model, Pharmaceutical Society of Japan, Tokyo, 1973, p.38.

12) K. Fujisawa: Synthetic judgement of hepatic functional examine. "The Liver (I)," ed. by T. Oda, Doubun syoin Co., Tokyo, 1987, pp.294-304.

13) T.S. Chen and P. S. Chen: "Essential hepatology," Igaku shoin Co., Tokyo, 1982, p.26.

14) M. Mourelle, J. L. Amezcua and V. P. Alvarez: Reduction of apparent indicators of liver cirrhosis in rats by the arachidonate lipoxygenase inhibitor BW755C, Eur. J. Pharmacol., 134, 175-180 (1987).

15) D. Kershenobich, F. Vargas, T. G. Garcia, R. P. Tamayo, M. Gent and M. Rojkind: Colchicine in the treatment of cirrhosis of the liver, N. Engl. J. Med., 318, 1709-1713 (1988).

16) D. Kershenobich, M. Uribe, G. I. Suarez, J. M. Mata, R. P. Tamayo and M. Rojking: Treatment of cirrhosis with colchicine, Gastroenterol., 77, 532-536 (1974).

17) P. M. Simmons, J. A. Salmon and S. Moncada: The release of leukotriene $B_{4}$ during experimental inflammation, Biochem. Pharmacol., 32, 1353-1359 (1983).

18) D. Gemsa, W. Kramer, M. Brenner, G. Till and K. Resch: Induction of prostaglandin $\mathrm{E}$ release from macrophages by colchicine, J. Immunol., 124, 376-380 (1980).

19) P. Henricks, M. D. Tol, R. J. H. Kats, F. P. Nijkamp and J. Verhoef: Differences in the effect of arachidon- 
ic acid on polymorphonuclear and mononuclear leukocyte function, Biochem. Biophys. Acta, 801, 206-214 (1984).

20) S. Yoshimoto, T. Yoshimoto and E. Tsubura: Arachi- donic acid-induced chemiluminescence of human polymorphonuclear leukocytes, Biochem. Biophys. Res. Commun., 107, 779-784 (1982). 